\title{
O arquipélago imaginário do corpo virtual
}

\author{
Jean-Jacques Wunenburger
}

O corpo certamente designa, em primeiro lugar, uma realidade objetiva e biológica dotada de órgãos, funções, fronteiras e superfícies, mas a nossa relação pessoal, subjetiva e íntima com o corpo se desenvolve também por meio de um conjunto de representações que o modificam, sobrecarregam-no de valores negativos ou positivos, transformam seu estado natural ou suas aparências sensíveis. As imagens de nosso corpo formam-se tanto em sua vertente interior, imagens de prazer, de sofrimento, de patologias, quanto em sua vertente exterior, em sua superfície visível, estando sua nudez primeira revestida não somente de vestes, como também de signos, e estendida até mesmo a gestuais e máscaras. Nossa experiência do corpo efetivo oscila, pois, entre um corpo real acessível ao olhar da ciência e à sua manipulação, e um corpo virtual feito de possíveis, de devaneios, de fantasias, de irrealidades que o podem esvaziar, expandir, duplicar, mascarar, ou mesmo fazê-lo desaparecer paulatinamente, reduzi-lo a nada em sua própria vida. O sobrecorpo produzido inicialmente pelos sonhos pode tomar um aspecto material, inscrever-se em artefatos sensíveis por meio do jogo de imagens que vão, atualmente, da pintura à eletrônica. Hoje em dia, a cultura tradicional, intemporal e transcultural do corpo conhece, sem dúvida, certas inflexões, explorações inéditas, passagens do limite, técnicas e estéticas, que não deixam de nos questionar a respeito de suas formas, interesses e conseqüências. O corpo efetivo individual inscrito naturalmente na finitude do tempo e da morte vem sendo substituído cada vez mais pelo corpo virtual, acelerado ou eternizado, mutável ao menos, mutante, plástico até não poder mais. Em que sentido? Pode-se conferir unidade a expressões tão diferentes quanto o corpo numérico das imagens de síntese e o corpo potencial das biotecnologias que conduzem a uma antropogenia (cirurgia estética, próteses, dopagem, manipulação genética etc.)? Quais seriam as fontes filosóficas das experimentações de uma "sobrenatureza" (teosofia da imago, gnoses, alquimia etc.)? Que interesses estão em jogo e quais são as conseqüências relacionadas com a própria idéia de uma 
Natureza ("bios" dotado de um "télos" na concepção de Aristóteles) do vivente?

\section{O jogo dos corpos duplos}

A experiência racional leva a convencermo-nos de que nosso corpo é uma realidade psicoquímica e biológica com formas determinadas e únicas que se deixam objetivar sob a forma do corpo nu. No entanto o corpo, materializável, observável a olho nu e identificável em sua singularidade pelas ciências, é geralmente escondido (pela roupa) e modificado em sua naturalidade primeira pelas artes de viver em sociedade. É uma característica cultural produzir uma cultura do corpo, um conjunto de ritos e mitos que o fazem integrar uma imageria, um imaginário, uma imago mesmo, alguns dos sistemas de imagens que vêm revestir sua unidade nua.

A mais antiga marca de humanidade começa com a marcação do corpo que desvirtua a pele de sua natureza bruta. Bem antes da sepultura, a hominização começa, sem dúvida, pela inscrição dos signos no corpo. Se o animal evolui em um mundo de índices e de sinais, chegando até a estruturar códigos de comunicação, ele nunca realiza sobrecargas cosméticas. Por mais rudimentares que sejam os homens, eles personalizam seus corpos por meio de uma artialização, que não é ainda artificialismo. O cumprimento dos pêlos, as escarificações, as tatuagens e as pinturas são algumas técnicas, mínimas que sejam, para fazer com que o corpo biológico passe a integrar um universo humano, o de um sentido, de crenças ou, simplesmente, de uma aparência mediada, bonificada, codificada. Assim, o corpo amplia crenças religiosas e ideais estéticos porque, previamente, sua superfície não é somente um limite do corpo efetivo, mas uma superfície exposta que opera como um texto. A partir disso, aliás, a pele se vê tratada menos como limite exterior do interior do corpo, e mais como superfície aberta para fora, exposta ao conjunto dos signos sociais e cósmicos. ${ }^{1}$

O dispositivo de revestimento dérmico se estende, normalmente, pelo artefato da roupa, que vem sobrecarregar a pele de formas e cores, que, geralmente, vão além de uma finalidade puramente funcional. A roupa nunca serviu apenas para pro-

${ }^{1}$ A respeito do corpo sem interioridade, cuja superfície é aberta para fora, ver Leenhardt, Maurice. Do Kamo: la personne et le mythe dans le monde mélanésien (Paris: Gallimard, 1947). 
teger, mas para adquirir ou assumir uma condição, um papel, um lugar em uma hierarquia. De um modo mais refinado e intermitente, os ritos criam a ocasião para se usarem máscaras, fantasias, desenhos simbólicos, para se acompanharem os jogos de imitação ou possessão. O corpo se torna, então, um portaestandarte que exibe um caleidoscópio de invenções de signos e símbolos. Nesse sentido, a festa constitui a instituição, por excelência, de uma teatralidade barroca do corpo nu, incluindo as mais estranhas metamorfoses (em animais) por meio do jogo de uma encenação com um toque de crenças. * Assim, todas essas práticas participam mesmo de uma imageria do corpo, que reúne um conjunto de formas plásticas, gráficas, coloridas ou não, que permitem decorá-lo, marcá-lo com signos, recobri-lo com textos e imagens.

Chega-se a uma nova etapa quando o corpo real se vê efetivamente transformado para assemelhar-se a um corpo previamente imaginado. Se bastava decorar a pele, passa-se, agora, a deformá-la, para conformá-la a um tipo não-natural, a um artefato. Recorre-se, então, a uma técnica de remodelagem das obras da natureza a partir de um protótipo imaginado pelo homem. Assim como a vida física conhece os estados modificados de consciência, por meio de técnicas de êxtase ou transe, também o corpo se vê submetido a modificações que tendem a conformá-lo a um corpo imaginário, a um corpo de sonho. Geralmente, tais técnicas são do âmbito de intervenções localizadas (ritos de deformação de membros e orifícios, no caso dos lábios alargados ou dos pés comprimidos etc.) ou de experiências transitórias, efêmeras, em que se experimentam, momentaneamente, poderes inesperados do corpo (orgia, atividade esportiva, ritos de transe e possessão) ou, de modo mais banal, de roteiros literários (na ficção científica, por exemplo). As transformações do corpo, destinadas a substituir o corpo herdado da natureza por um corpo desejado e planejado pela mente, estiveram, durante muito tempo, limitadas por causa de meios técnicos rudimentares. Mas sob a pressão da pesquisa médica, da sua experimentação mesmo, pode-se, desde então, substituir órgãos do corpo por aparelhos mecânicos ou eletrônicos, próteses que remodelam o corpo e melhoram suas performances naturais. Diversas técnicas de injeção hormonal e de cirurgia acarretam até modificações biológicas do corpo, dos órgãos sexuais, de suas performances atléticas etc. A técnica, ao inserir o artefato na vida, materializa, portanto, imagens do
"Wunenburguer, Jean-Ja. cques. La fête, le feu et le sacré. Paris: Ed. Universi. taires, 1997).

* (Cf. Traverses, n. 14.15: Panoplies du corps. Paris: Centre Georges Pompidou, 1979). 
corpo que se julgavam pertencer à ficção pura (a prótese, órgão mecânico enxertado, em seguida, informático, o chip, a biônica ou a dopagem química). ${ }^{2}$

Experimentos marginais dessa natureza estão mesmo em via de serem considerados como uma modalidade comum da biotecnologia contemporânea que tem a ambição de retificar a forma orgânica, intervindo cada vez mais cedo (nos genes) e de modo cada vez mais profundo. Se, freqüentemente, a transformação do corpo é motivada pela busca de uma ortomorfologia, de um corpo perfeito e ideal, ela também pode mesclar-se com objetos terapêuticos, se ocorrer que determinadas configurações de nascença se entendam como anomalias ou monstruosidades. Sejam quais forem as finalidades, terapêuticas, estéticas ou lúdicas, esses empreendimentos vão atrás, no mínimo, de um corpo de sonho que, por intervenção médica, deve tornar-se corpo real. Aliás, pouco a pouco, o vivente se vê substituído pelo cibernético, e o artefato eletrônico permite, de algum modo, aperfeiçoar a modificação, fazendo-a escapar dos imprevistos do biológico puro. Com a biônica, os processos da vida se vêem cada vez mais duplicados, e mesmo substituídos por programas informáticos que substituem regulações biológicas inatas. A transferência do vital para o eletrônico via mecânica permite, pois, que se obtenha um corpo sob encomenda e se materialize um corpo previamente modelado por pensamento onírico. Não surpreende, portanto, ver a medicina realizar os projetos mais inacreditáveis da ficção científica.

Em todas as intervenções, o corpo serve como suporte, veículo para uma fantasmagoria de imagens mais ou menos significantes, ou como matéria-prima para transformações artificiais, isto é, que nunca foram produzidas somente pela informação espontânea da natureza. Em ambos os casos, porém, os corpos revestidos por imagens ou postos em conformidade com imagens continuam apreendidos como realidades singulares. Se ele materializa em sua superfície uma rica produção de imagens, não leva a que se questione seu ancoradouro biológico peculiar. Bem diferente se revela o filo de imaginário do "corpo-imago", que remete a diferentes imagens que dividem a forma físico-biológica, para servir como suporte espacial, embora imaterial, para um indivíduo. Diferentemente da imageria, o termo "imago" pode servir, com efeito, para designar

\footnotetext{
${ }^{2}$ Ver, por exemplo, o trabalho de Orlan.
} 
imagens de realidades não imediatamente visíveis no mundo dos sentidos, mas que, no campo das percepções psíquicas, integram objetos que têm consciência própria, sem depender da fantasia ou da fantasmagoria de uma consciência. ${ }^{3}$ Nesse caso, a individualidade encarnada não se limita mais ao corpo imediato de carne e ossos, estendendo-se a um segundo corpo que, primeiramente, mesmo por ser visualizável, nem por isso é menos um corpo sem matéria, um corpo-imagem.

As culturas arcaicas, então, não deixaram de dar prioridade, no imaginário de seus ritos e mitos, a desdobramentos da forma físico-biológica dos indivíduos. Nelas verificamos a crença bastante geral de que o corpo material não passa de um dublê de uma outra forma, o corpo etéreo que serve como verdadeiro envelope para a alma, ou seja, para o princípio da animação.* É justamente por isso que, depois da morte do corpo biológico, o indivíduo pode sobreviver a si em seu corpo duplo, que o faz pertencer a uma outra ordem de espaço e de tempo diferente do momento de sua passagem por este mundo encarnado. Rico, portanto, é o arsenal de imagens espectrais ligadas aos ancestrais que retornam a este mundo, como se observa, por exemplo, na estatuária grega do kolossos. Como mostrou JeanPierre Vernant, o kolossos representa uma espécie de duplo físico dos indivíduos mortos, pequeno ídolo que serve como memorial e cuja forma plástica vem da reprodução visível do corpo invisível. O kolossos seria, assim, menos uma cópia, retrato de um ser que existiu em carne e ossos (como se uma fotografia lembrasse o ser falecido), que a fabricação do duplo de um duplo ou, dizendo de outra maneira, a imagem visível do corpo de glória que nunca morre.* Poder esclarecer esses fenômenos em termos racionais com modelos de psicopatologia não invalida que as visões do duplo* tenham encontrado espaço na cultura em que foram incorporadas aos ritos religiosos ou xamanistas (em que o duplo permite que se exista por teletransportação).

As religiões monoteístas, de diversas maneiras, aculturaram o campo de visões de um corpo sobrevisível. Uma das

\footnotetext{
${ }^{3} \mathrm{O}$ termo foi empregado, pela primeira vez, por H. Corbin, para designar imagens dotadas de uma realidade independente da nossa subjetividade, que permitem visualizar realidades inteligíveis. Ver Corbin, Henry. L'imagination créatrice dans le soufisme d'Ibn' Arabi (Paris: Flammarion, 1958).

${ }^{4}$ Tema explorado por Henri Bergson em Les deux sources de la morale et de la religion (Paris: PUF, 1945).
}

"(Tansley, Dadid V. Le corps subtil: essence et ombre. Paris: Seuil, 1977).
"(Vernant, Jean-Pierre. "La catégorie psychologique du double". Em: Mythe et pensée chez les grecs. $\mathrm{Pa}$ ris: La Découverte, 1996)

" (Rank, Otto. Don Juan et le double. Paris: Payot, 1973) 
"(Cf. Brion, Marcel. Les pein tres de Dieu. Paris : Félin/ Philippe Lebaud, 1996).

* (Quéau, Philippe. Le virtuel, vertus et vertiges. Pa. ris: Champ Vallon, 1993).

"(Platão. Le Sophiste. Paris: Flammarion, 1993).

" (Le Breton, David. "Les artifices du désir: de l'androïde à la cybersexualité". Em: Mouchès, A. (dir.). De l'illusion psychique aux illu sions sociales. L'Harmatan, 1999).

"(Quéau, Philippe. Le virtuel, vertus et vertiges. Ob. cit.). formas mais inovadoras e espetaculares do corpo-imago, como forma visível do corpo imaterial, ocupa o centro dogmático do cristianismo, para o qual a figura divina, após um período de encarnação antropomórfica, supostamente reaparece diante dos olhos dos fiéis na forma de corpo espectral, em um corpo de ressurreição e de glória. A morte de Deus, que se fez carne e homem, não conclui, de fato, seu desaparecimento puro e simples do mundo. O tema da ressurreição, posterior à descoberta do túmulo vazio, é acompanhado por uma reaparição para os homens na forma de corpo de ressurreição, de figura corpórea imaterial, de corpo de luz livre do peso opaco da matéria. É justamente essa a força inacreditável do quadro de Grünewald que mostra um Cristo em plena glória saindo do túmulo, estando seu corpo irradiado por uma luz interior que se torna puramente translúcida.* O Cristo ressuscitado se torna, pois, um caso exemplar de uma cultura da “imago", em que o corpo divino toma de empréstimo uma forma visível para sobreviver em um terceiro mundo intermediário que não é redutível nem ao corpo mortal, nem à imortalidade desencarnada.

Enfim, conviria pôr à parte um corpo propriamente "fantástico" (do grego "fantasma”, equivalente de "eidolon”), que substitui o corpo vivente por um corpo sintético, ou seja, numérico. ${ }^{*}$ De acordo com as indicações já fornecidas por Platão, o "fantasma” designa, em grego, uma realidade puramente ilusória, pura aparência sem corpo, ainda que dê impressão de realidade. Para Platão, os deuses, como os homens, podem produzir os "fantasma", que designam tanto realidades aparentemente sem conteúdo quanto representações mentais sem objeto correspondente. ${ }^{*}$ Se, durante muito tempo, os simulacros da corporeidade pareciam limitados aos sonhos psíquicos (corpo erótico do sonho noturno) ou às imagens em trompe-l'oeil (algumas imagens eróticas e pornográficas), atualmente eles parecem dar um passo à frente, por intermédio da imagem de síntese numérica que é acompanhada por tais efeitos sensoriais sem que um corpo biológico em carne e ossos corresponda às sensações.* A imagem de síntese permite, então, duplicar um corpo com um outro desdobramento, a partir de informações algorítmicas, que reconstituem as propriedades anatômicas e psicológicas do primeiro. Após a simulação numérica, o duplo do corpo atinge, pois, uma espécie de sobre-realidade que, para o olho, e sem tardar para o tato, pode desempenhar a função de corpo real.* Afinal de contas, o corpo inteiramente artificial 
toma, de fato, o lugar do corpo natural, imitando, até à perfeição, as características da vida. O corpo, no sentido estritamente virtual, assinala, portanto, o desaparecimento da vida em benefício de sua simulação e, a partir de então, a imagem do corpo não remete mais a um referente exterior que possa agir como referente ontológico primeiro e último. Temos presenciado, de fato, uma espécie de sobre-realidade, e não uma irrealidade.

Assim, se confirma a existência de diferentes dispositivos de imagens que vêm completar o corpo real ou substituí-lo. Todas essas categorias têm uma história antiga e estão localizadas nos códigos e ritos culturais, mas já se pode entrever o quanto a imageria e também a imago parecem ter passado por alguma regressão, ao passo que a busca do corpo imaginário ou fantástico foi objeto de investimentos simbólicos e técnicos sem precedentes, confirmando, assim, o sentimento de que nossos contemporâneos procuram menos brincar com seu corpo, revestindo-o ou desdobrando-o, do que trocá-lo radicalmente por um corpo artificial, até o seu desaparecimento como um substrato biológico.

\section{A cacofonia do corpo virtual}

$\mathrm{O}$ que querem dizer os deslocamentos recentes das imagens do corpo, e que problemas eles suscitam? Estamos mesmo diante de uma tendência uniforme e coerente ou ela mascararia tensões, quiçá contradições significativas de nossos próprios problemas não resolvidos com nosso corpo? Um primeiro balanço, bastante empírico, das práticas e de suas incoerências pode ser vislumbrado.

Primeiramente, tudo parece provar que, com maior freqüência, temos lidado, no imaginário contemporâneo, com um entrecruzamento, até mesmo com uma superposição, de imagens. Assim, a fascinação exercida pelas técnicas de clonagem, que permitiriam a reprodução idêntica de um ser humano sem recorrência ao cruzamento genético da bissexualidade, sem dúvida reativa, no inconsciente individual ou coletivo, a visada de um duplo imaterial característico das religiões do além. O desejo de autoconservação de si, de auto-reparação mesmo, e com fins de imortalidade, mantido pelas promessas da clonagem, longe de ser provocado apenas por proezas das biotecnologias, enraizar-se-ia na memória arcaica do corpo místico, que, visto por um determinado prisma, está no oposto de qualquer domínio prometéico sobre o corpo.* Assistir-se-ia, pois, 
tanto a um reforço de um mito científico por um mito mágicoreligioso quanto a um tipo de contradição entre uma crença pré-científica e uma utopia hipercientífica do corpo. Por outro lado, uma mesma conquista biotécnica pode pôr-se a serviço de fins opostos. Então, o desenvolvimento das próteses que substituem órgãos naturais por uma maquinaria artificial se dispõe ora a melhorar, transgredir mesmo, as características do corpo natural, permitindo esperar dos progressos da ciência um corpo de super-homem e, logo, um novo tipo de vida que permita ultrapassar os limites da condição humana, ora apenas a garantir uma perfeita regulação do corpo existente, servindo os diferentes aparelhos eletrônicos somente para maximizar a informação biológica, sem tocar na identidade psicobiológica do indivíduo. Assim, a prótese pode ser utilizada para se produzir um outro corpo ou para se obter um corpo que funcione automaticamente (pela intervenção de chips que internalizem informações externas no cérebro através de captadores). Apesar da irresistível pesquisa de técnicas de transformação do corpo em artefato, parece mesmo que ela se desenvolve fundamentada em um sincretismo de motivações, em uma ambivalência de finalidades, em uma coexistência de dois paradigmas culturais: um pólo mágico-religioso e outro técnico-científico, o que se verifica claramente no âmbito da ficção científica e no bazar temático da retórica da "New Age".

No entanto, em linhas gerais, as buscas contemporâneas de um neocorpo são unânimes em negar um "télos", uma forma do corpo que se cumpriu. Em seu conjunto, os tratamentos simbólicos do corpo antes da era tecnocrática pressupunham, a exemplo do pensamento de Aristóteles, que os corpos, como todos os seres da Criação ou da Natureza, seriam dotados de uma espécie de fim natural, que constituiria sua essência. Cada coisa, em conformidade com a harmonia do cosmos, devia realizar sua natureza, ou seja, deixar que se desenvolvessem propriedades virtuais, potenciais, até atingir um tipo de forma última e que foi cumprida. Mesmo se diversos obstáculos limitavam a realização perfeita do corpo (defeito de nascença, monstruosidade, doença, acidente), ela podia ser identificada, definida, estimulada e pesquisada. Ao contrário, o triunfo do prometeísmo faz com que o corpo não seja mais apenas um material genético, fisiológico e biológico disponível para todo tipo de manipulação, reestruturação e transformação, mesmo se for necessário dar fim a processos tidos até então como irre- 
versivelmente naturais. O corpo se torna, pois, um objeto vivo instrumentalizável que se pode dividir em pedaços, consertar, recriar, desconsiderando-se um modelo absoluto. Assim, temse assistido a um novo questionamento de um corpo perfeito definido por uma essência, em benefício de um puro corpo de desejo, trabalhável ao infinito, disponível para as mais variadas fantasias. Nessa perspectiva, observa-se não somente uma revolução de princípios filosóficos, mas também um empobrecimento dos modos de interpretação do corpo. O nosso imaginário contemporâneo que entende o corpo como algo profundamente disponível se caracteriza, pois, por uma perda de memória de uma cultura hermética do corpo, que jogava com os múltiplos planos e suas potencialidades simbólicas complexas (corpo da cabala, Paracelso). O tecnicismo entregue apenas ao gozo se paga, assim, com o preço de um corpo unidimensional e, para dizer a verdade, dessimbolizado.

Essa perspectiva, essa inversão mesmo, pode, enfim, ser corroborada pela sobrevalorização da questão das formas do corpo, em detrimento das forças que o movem ou situam-no sob seu controle. As técnicas materiais (químicas, cirúrgicas, informáticas) permitem, sem dúvida, modificar os caracteres do corpo no espaço, mas conferem pouco controle sobre as energias psicossomáticas que, ao contrário, mereciam uma atenção crescente na cultura tradicional (energias orientais, parapsicologia, técnicas do corpo ou da consciência corporal, estados modificados de consciência). Esta, indiferente ou impotente para mudar as formas biológicas, concentrava sua busca de poderes nas forças mentais capazes de modificar os estados do corpo. O exercício repetido, a iniciação e a cultura de dons permitiam que se tivesse, paulatinamente, domínio sobre o corpo, pouco modificado em si mesmo. Por outro lado, verifica-se, atualmente, um tipo de amnésia dos poderes psíquicos, de sua conquista, de seu domínio progressivo no tempo, em benefício único das intervenções mecânicas sobre a morfologia. Parece mesmo haver dificuldade crescente para harmonizar as duas culturas do corpo, exigindo a segunda referência a uma entidade psíquica, a alma, que é uma potência para animar o corpo-máquina.

Ao cabo dessas indicações sobre os tipos de imaginário do corpo e suas evoluções contemporâneas, podemos nos arriscar em algumas observações sobre as tendências profundas da cultura do corpo, cada vez mais associada à categoria do virtual. 
Em primeiro lugar, se o adjetivo "virtual" parece se ter imposto para agrupar diversas abordagens técnicas e icônicas do corpo, é de temer que, de fato, trate-se apenas de uma falsa unidade nominal porque o termo tende a cruzar usos muito diferentes. O virtual ora quer dizer "em potência", em comparação com o real, atual, em ato, caracterizando, assim, os possíveis laterais e as formas irreais, antes que se lhes dê um conteúdo ou um suporte efetivo no campo das biotecnologias, por exemplo; ora equivale, ao contrário, a uma substituição do vivente por informações numéricas que podem dar corpo a uma pura simulação. No primeiro caso, o virtual se refere a um imaginário que pode materializar-se no corpo de carne; no segundo, no entanto, a imagem informatizada toma o próprio lugar do corpo de carne. $\mathrm{O}$ virtual continua sendo, pois, um termo equivocado e rico em conotações, novidades e elementos fantásticos, mas cujos efeitos de real são muito divergentes. Não se podem tomar como equivalentes um corpo vivo, dopado e dotado de maquinarias, e uma máquina que se toma em lugar de um corpo.

Independentemente de sua ambigüidade primeira, não se deve negligenciar que todas as buscas estão atravessadas por uma visada comum, que pode ser resumida pela busca de um corpo outro, conjugado de diferentes modos: alterado, alternativo ou alienado (com perda de identidade). As diferentes variedades de imagens fazem parte de uma modificação da identidade empírica existencial do corpo efetivo, seja para enriquecê-lo, torná-lo híbrido ou mudar de corpo. Por isso, todas essas práticas se guiam por um desejo de metamorfose de si, de escape da finitude, de acesso a estados ontológicos diferentes. A experiência de alteração de si na esfera do corpo vivo, todavia, segue caminhos muito opostos: ela se realiza com uma sobrematerialização (tatuagem, prótese, dopagem) ou com uma desmaterialização (corpo glorioso, imagem de síntese). Ademais, essa busca visa não somente a uma multiplicação ou a uma deformação do corpo, mas também a uma modificação das suas fronteiras, fazendo o mundo retornar para dentro do Eu ou expandindo os limites corporais para fora. Daí verificarse, novamente, uma espécie de retorno à questão arcaica das fronteiras invisíveis e móveis do corpo, tais como foram eviden-

" (Leenhardt, Maurice. Do Kamo: la personne et le mythe dans le monde méla. nésien. Ob. cit.). ciadas por M. Leenhardt, com base em um questionamento do ego também no âmago da crise da época pós-moderna."

A aparição das novas técnicas de representação do corpo nos confronta, portanto, com problemas novos, relacionados 
tanto com técnicas objetivas quanto com a relação subjetiva consigo. Entretanto, apesar das modificações aparentes, nossa relação contemporânea com o corpo continua confrontada com a mesma hesitação - eterna e intemporal - entre uma simples visada lúdica, em que a imagem serve para brincar, durante o tempo de um jogo (pelo prazer da máscara, da exploração dos possíveis), com um corpo do qual nunca esquecemos a fragilidade e a mortalidade, e a busca de uma verdadeira transformação ontológica (que se pode chamar de tornar-se divino, imortal etc.), que visa a uma mudança de natureza, uma assunção definitiva do corpo. Mas que se mantenha horizontal a experiência, nos jogos do corpo, ou que se torne vertical, fazendo parte de uma "ontólise"*, o encontro do corpo com suas imagens, entre as quais a mais constante, patética ou grotesca seria o desejo de sair da prisão do Eu, nunca está isento de interesses metafísicos.

Tradução

Matosalém Vilarino

\section{Jean-Jacques Wunenburger}

Professor de Filosofia geral da Universidade Jean Moulin, Lyon 3 (França) e membro do Centro de estudos de sistemas. Co-diretor, depois de tê-lo dirigido por muito tempo, do Centro Gaston Bachelard de pesquisas sobre o imaginário e a racionalidade da Universidade da Bourgogne. Também dirige os Cadernos Gaston Bachelard, o Boletim dos Centros de informação de pesquisas sobre o imaginário. Ao lado de trabalhos de filosofia do conhecimento e de ética, dedicou-se mais particularmente ao estudo do lugar e do papel das imagens, símbolos e mitos nas obras artísticas, científicas e filosóficas.

\section{Resumo}

Se corpo designa, em primeiro lugar, uma realidade objetiva e biológica, a nossa relação, pessoal, subjetiva e íntima com ele se desenvolve-se por meio de um conjunto de representações que o modificam, sobrecarregam-no de valores negativos ou positivos, transformam seu estado natural ou suas aparências sensíveis. Nossa experiência do corpo efetivo oscila entre um corpo real acessível ao olhar da ciência e à sua manipulação, e um corpo virtual feito de possíveis, de devaneios, de fantasias, de irrealidades que o podem esvaziar, expandir, duplicar, mascarar ou mesmo fazê-lo desaparecer. A apari-
" (Brun, Jean. Le retour de Dionysos. Paris: Desclée et Cie., 1969).
Palavras-chave representação corpo real corpo virtual 
Key words

representation

real body

virtual body

Mots-clé

representation corps réel corps virtuel
Recebido em 17/03/2006

Aprovado em 22/05/2006

ção de novas técnicas de representação do corpo nos confronta com problemas novos, ligados tanto com as técnicas objetivas quanto com a relação subjetiva. Entretanto, apesar das modificações aparentes, nossa relação contemporânea com ele continua confrontada com a mesma hesitação entre uma simples experiência lúdica com um corpo do qual nunca esquecemos a fragilidade e a mortalidade, e a busca de uma verdadeira transformação ontológica, que visa a uma mudança de natureza e à sua assunção definitiva.

\section{Abstract}

If one may take the body to mean, first and foremost, an objective and biological reality, our personal, subjective and intimate relationship with should also be considered, as it is developed by means of a whole set of representations that modify it, overloading the body either with negative or positive representations, and transforming its natural state or sensible appearance. Our experience of the effective body oscillates between a real one visible to the scientific gaze and prone to be manipulated by it, and a virtual body made of possibilities, daydreaming, fantasies and irrealities, which may empty out, expand, double, disguise or even extinguish it. The emergence of new representational techniques poses new problems to us, which refer to both objective techniques and subjective relationships. Nonetheless, for all apparent modifications, our contemporary relationship with our bodies is still characterized by the same hesitancy between a simple, playful experience of a body whose frailty and mortality cannot be forgotten, and the search for a truly ontological transformation aiming at a change of nature and a definitive a definitive assumption of the body.

\section{Résumé}

Si le corps désigne, tout d'abord, une réalité objective et biologique, notre relation personnelle, subjective et intime avec lui se développe aussi par le moyen d'un ensemble de représentations qui le modifient, qui lui imposent des valeurs négatives ou positives, qui transforment son état naturel ou ses apparences sensibles. Notre expérience du corps effectif bascule entre un corps réel accessible au regard de la science et à sa manipulation, et un corps virtuel fait de possibilités, de songes, de fantaisies, d'irréalités qui peuvent le vider, l'intensifier, le doubler, le masquer, et même le faire disparaître. L'apparition de nouvelles techniques de représentation du corps nous met face à de nouveaux problèmes, liés aux techniques objectives mais aussi aux relations subjectives. Cependant, malgré ces modifications apparentes, notre relation contemporaine avec le corps est toujours confrontée à la même hésitation entre une simple expérience ludique avec un corps dont on n'oublie pas la fragilité et la mortalité, et la quête d'une véritable transformation ontologique, qui vise à un changement de nature, à une assomption définitive du corps en tant que tel. 